\title{
The Effects of Optimal Time of Day on Persuasion Processes in Older Adults
}

\author{
Carolyn Yoon \\ University of Michigan \\ Michelle P. Lee \\ Singapore Management University \\ Shai Danziger \\ Ben Gurion University
}

\begin{abstract}
Past research demonstrates that the majority of older adults (60 years and older) perform resource-demanding tasks better in the morning than in the afternoon or evening. The authors ask whether this time-of-day effect also impacts persuasion processes performed under relatively high involvement. The data show that the attitudes of older adults are more strongly affected by an easy-to-process criterion, picturerelatedness, at their non-optimal time of day (afternoon) and by a more-difficult-to-process criterion, argument strength, at their optimal time of day (morning). In contrast, the attitudes of younger adults are affected primarily by argument strength at both their optimal (afternoon) and non-optimal (morning) times of day. Process-level evidence that accords with these results is provided. The results accentuate the need for matching marketing communications to the processing styles and abilities of older adults. (C) 2007 Wiley Periodicals, Inc.
\end{abstract}

Over the past decades, the number and collective purchasing power of older Americans has increased dramatically. Recent reports indicate that Americans over 55 years old are "staying younger longer," that they spend 
more on packaged goods than any other age group, and that they spend disproportionately on food and drink (Parry \& Longman, 2004). Similar patterns have been observed throughout the industrialized world, particularly in Western Europe and Japan. Despite the significance that this demographic shift should have for marketers, companies in industrialized countries still spend approximately 95 percent of their advertising and marketing budgets on those under the age of 50 ("Over 60 and Overlooked," 2002).

While it has been slow to occur, the authors speculate that marketers and public policy makers will increasingly target the so-called "gray market." Unfortunately, little is known about how older adults respond to persuasion attempts. The paucity of studies directly addressing this issue is surprising, given the accumulated knowledge concerning the effects of aging on basic cognitive functions (Craik \& Salthouse, 2000) and changes to the human brain (Reuter-Lorenz \& Lustig, 2005). The picture that has emerged from this research is that performance on tasks that require extensive processing, involve integration of to-be-remembered information with context, or draw significantly on working memory declines steadily throughout adulthood. Applied to persuasion, these findings imply that the response of older adults to persuasion communications will be moderated by the effort entailed by such processing.

The present research examines whether, in older adults, the contribution to attitude formation of message components that require different amounts of processing resources are systemically affected by the time of day at which processing takes place. An answer to this question will provide insight regarding the effective communication of information to this large and growing population. For instance, older adults may be found to be less capable of processing resource-demanding information at their non-optimal time of day, which could lead to difficulty in arriving at valid conclusions regarding persuasion materials. Importantly, at such times older adults may exhibit increased susceptibility to undue influences of false claims. Such vulnerability is particularly worrisome as older people receive the bulk of information about products from mass media advertising, much of which is not scrutinized (Spotts \& Schewe, 1994; Nussbaum et al., 2000). Moreover, because old age is a period characterized by changing social roles (Schewe \& Balazs, 1992; Kim, Kang, \& Kim, 2005), reduced self-esteem (Loroz, 2004), physical decline, and cognitive deficits, the elderly are more likely than other age groups to fall prey to fraudulent and unethical marketing practices. Indeed, there is evidence for an increase in the incidence of scams and questionable marketing tactics targeting older consumers (AARP Foundation, 2003). By determining when older adults will elaborate on the content of a message and engage in thoughtful consideration of persuasive information, it will be possible to offer some guidance to marketers, advertisers, and policy makers on ways to design communications targeting the elderly that minimize undue influences. 
The paper is organized as follows. First, literature is reviewed that suggests that available cognitive resource systematically affects the processing of persuasion messages (Chaiken, Liberman, \& Eagly, 1989; Petty, Cacioppo, \& Schumann, 1983). Next, findings are reviewed which indicate that older adults' ability to extensively process information is greater in the morning than in the afternoon. A synthesis of these two literatures lead the authors to the hypothesis that older adults attitudes will be based on simple-to-process, less resource-demanding message information at their non-optimal time of processing (afternoon) and on more complex, resource-demanding information at their optimal time of processing (morning). Finally, an experiment is presented that tests this hypothesis.

\section{THE EFFECTS OF COGNITIVE RESOURCE ON PROCESSING OF PERSUASION MESSAGES}

Contemporary theories of persuasion propose that responses to persuasive messages vary in the extent to which they are formed or changed based on relatively thoughtful resource-demanding, as opposed to nonthoughtful, processes (Chaiken et al., 1989; Petty \& Cacioppo, 1986). Generally, these theories posit that a shift from non-thoughtful to thoughtful processing is contingent on the motivation, ability and opportunity to process. According to the heuristic-systematic model (Chaiken, 1980, 1987; Chaiken et al., 1989), there are two fundamental informationprocessing modes. When processing systematically, perceivers access, scrutinize, and integrate all useful information to reach a judgment. In contrast, the heuristic processing mode involves the use of prior knowledge structures in the form of simple decision rules, or cognitive heuristics, to reach judgments. According to the model, either or both processing modes may operate in a given setting, with the likelihood of systematic, resourcedemanding processing increasing when motivation, ability and opportunity are high. The Elaboration Likelihood Model (ELM; DeMarree, \& Petty, in press; Petty et al., 1983; Petty, Priester, \& Briñol, 2002) also posits that motivation, ability, and opportunity moderate the impact of less and more resource-demanding information on persuasion. Specifically this theory posits that "peripheral route processing," which takes less effort, dominates when motivation, ability, or opportunity are low, while "central route processing," which takes more effort, dominates when the three are high. However, according to ELM, recipients decide a priori whether to choose the more effort-intensive "central" route of processing or the less effort-intensive "peripheral" route of processing, depending on their motivation, ability, and opportunity to do so.

For the purpose of the present study, the main implication of the two models is that when motivation is high and opportunity exists, then the resources available during processing will moderate the degree to which 
attitudes are based on message components that require extensive processing resources. Specifically, when a recipient has adequate resources, persuasion will be enhanced by the provision of strong and compelling arguments (Burnkrant \& Unnava, 1995; Petty et al., 1983). In contrast, when resources are lacking, persuasion will be based on easier-to-process aspects of the message, such as spokesperson attractiveness and the number of claims being made. In this study, an effort was made to maintain high motivation in all conditions so that the sole contribution of processing resources on persuasion could be examined.

\section{TIME-OF-DAY EFFECTS ON THE PROCESSING ABILITY OF OLDER ADULTS}

There is now much evidence that performance on a variety of cognitive tasks declines in older adults (Craik \& Jennings, 1992; Light, 1991; Zacks, Hasher, \& Li, 1999). The dominant explanation for this decline is a reduction in processing resources (Craik, 1986; Salthouse, 1991). Importantly, there is also evidence that processing resource fluctuates with the time of day. This is demonstrated by findings that the performance of older adults on cognitively taxing tasks is moderated by the time of day at which these tasks are performed (e.g., Hasher, Goldstein, \& May, in press; May, Hasher, \& Stoltzfus, 1993; Yoon, 1997). Specifically, a growing body of research has shown that for many older adults, performance on cognitively taxing tasks peaks in the morning and declines in the afternoon and evening. Importantly, due to their generally greater cognitive capacity, younger adults can process moderately resource-demanding information even at their non-optimal time of day (Yoon, 1997).

A synthesis of the aforementioned literatures concerning the processing of persuasive communications and cognitive resources leads to the following hypotheses:

H1: Older adults will rely on less resource-demanding information when evaluating a persuasive message at their non-optimal time of day and on more resource-demanding information when evaluating a message at their optimal time of day.

H2: Younger adults will rely on resource-demanding information when evaluating a persuasive message at both their non-optimal and optimal times of day due to sufficient processing resources even at their non-optimal time of day.

Next, these hypotheses are tested in an experiment in which older and younger adults evaluated a pain reliever described in a print advertisement at either their non-optimal or optimal time of day for processing. 
In four versions of the advertisement, argument strength and the relatedness of a picture to the pain reliever category ${ }^{1}$ were orthogonally manipulated. An effect of picture-relatedness on attitudes was assumed to reflect the contribution of a less resource-demanding message component on persuasion. An effect of argument strength on persuasion was thought to reflect the contribution of a more resource-demanding message component on persuasion. Because the authors were specifically interested in the effects of aging, time of day, and available resources on the processing of persuasive messages, performance was examined in a relatively high motivation condition without time constraints.

\section{METHOD}

\section{Participants}

Study participants were either younger adults (18 to 23 years old, $M=$ 20.9 ) or older adults (65 to 79 years old, $M=71.1$ ). The younger adults were recruited from an undergraduate subject pool at a large university, and the older adults were active, well-educated, community-dwelling volunteers recruited through a service organization affiliated with the same university. All participants had at least some college-level education $(M=13.8$ years for younger adults and $M=15.7$ years for older adults). Both younger adults $(M=3.7)$ and older adults $(M=3.8)$ reported their health as being at least average relative to others in their own age group. [Health ratings were assessed on a five-point scale $(1=$ much worse than average, $2=$ worse than average, $3=$ average, $4=$ better than average, and $5=$ much better than average).] Finally, individuals were selected on the basis of their scores on the Morningness-Eveningness Questionnaire developed by Horne and Ostberg (1976). Total scores on the questionnaire ranged from 16 to 86 with the following MorningnessEveningness categories: 16-30 (definitely evening), 31-41 (moderately evening), 42-58 (neither morning nor evening), 59-69 (moderately morning), and 70-86 (definitely morning). A total of 135 younger adults and 94 older adults were initially recruited for the study. Out of the 135 younger individuals, 36 (26.7 percent) who were classified as neutral types (neither morning nor evening types), and 7 (5.2 percent) classified as morning types were not included in the study sample. Of the 94 older adults recruited for the study, all but 6 fell into either the definitely morning or moderately morning categories (4 were neutral types and 2 were moderately evening types). Hence, 93.6 percent of the older adults were "morning types," a result consistent with previous findings that the vast majority of older adults tend to reach their mental peak in the morning (e.g., May et al., 1993; Yoon, 1997).

1 Prior research suggests that processing of simple pictures tends not to degrade with age (Park, Puglisi, \& Smith, 1986). 
Data for 92 younger subjects and 88 older subjects were thus retained for analysis. For this group older study participants had moderate to high morningness scores $(M=68.3)$, indicating that the morning was their optimal time of day, and all younger participants had moderate to high eveningness scores $(M=35.1)$, such that the evening was their optimal time of day, $F(1,178)=143.59, p<.001 .^{2}$

\section{Design}

The study was a 2 (Age: young vs. old) $\times 2$ (Time of day: morning vs. afternoon) $\times 2$ (Argument quality: strong vs. weak) $\times 2$ (Picture-relatedness: more related vs. less related) between-group factorial design.

\section{Stimuli}

The stimulus materials consisted of advertisements for nine different products presented to subjects in a booklet. To guide development of stimulus materials, several pretest studies were conducted with younger and older adults drawn from the same populations as the main study.

In the first pretest, 50 younger and 50 older subjects were recruited to determine which products to include in the booklet. Of particular concern was identifying a product that was equivalently regarded by both age groups in terms of familiarity, interest, and liking. Based on a pretest of 54 products, a pain reliever ${ }^{3}$ was chosen as the product to be featured in the critical ad and 8 other products (beverage, athletic shoes, camera, toothpaste, bar soap, drugstore, cereal, shampoo) were selected to serve as items appearing in filler ads. The critical product, a fictitious pain reliever called "Erazol," was presented fifth in the series of nine ads appearing in the booklet. The eight filler ads were real magazine ads, scanned and digitally manipulated to ensure similarity to the critical ad on the dimensions of graphical complexity, color print quality, and amount of text. These modifications ensured that the critical ad did not stand out, which might otherwise reveal its role as the ad of interest. In a similar vein, brands were included that ranged in their degree of familiarity to the subjects. While some of the ads featured brands that were widely available in the local market, and hence were likely to be familiar to subjects (e.g., Dove soap), others were sold in specific regional U.S. markets, but were locally unavailable (e.g., Quest mineral water).

As can be seen in Figure 1, the Erazol pain reliever ad consisted of three parts. The top part contained a color picture that was either related

2 It was not possible to cross the morningness/eveningness factor with age. Since very few younger participants in the study were morning types and virtually none of the older participants were evening types, the two factors in this study are confounded.

3 It is acknowledged that older adults may use pain relievers for a greater variety of pains (e.g., joints, arthritis), while younger people use them primarily for injuries and headaches. However, the pain reliever was chosen as the critical product because the two age groups reported equivalent levels of familiarity with, interest in, and liking for the product in a pretest. 


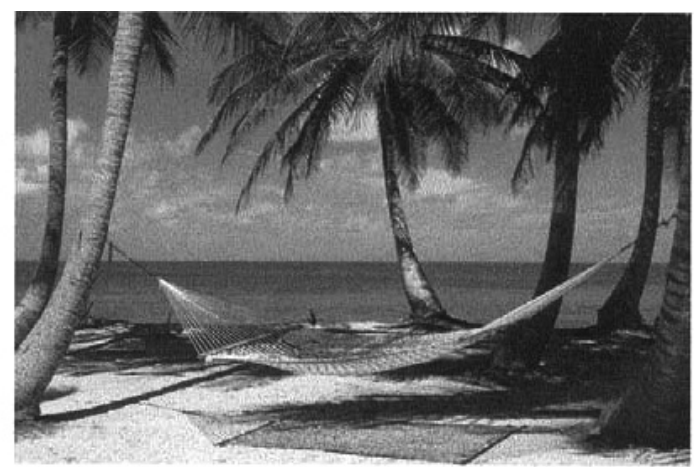

Designed for maximum relief.

Quality is backed by years of research and development.

Comes in tablets with a patented micro-thin coating that makes them easy to swallow.

Works well on headaches, muscular aches and pains, fever, and osteoarthritis pain.

In direct comparison tests, ERAZOL was preferred two to one over the nearest competitor.

Provides relief in just minutes.

\section{Introducing ERAZOL \\ THE PAIN RELIEVER YOU SHOULD TRY.}

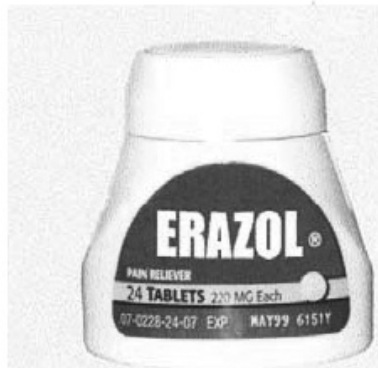

Figure 1. Example of the advertisement in the strong arguments/more-related picture condition.

or not related to the pain reliever product category. Below the picture were six statements that concerned the product. These were either strong arguments or weak arguments. The stimuli at the bottom of the page that did not change across experimental conditions consisted of a picture of the pain reliever bottle, the brand name, and slogan.

In a second pretest, 31 older and 31 younger subjects were recruited to identify pictures that varied in perceived relatedness to the pain reliever featured in the critical ad. Participants were given a randomly ordered set of 32 pictures, each of which was paired with a picture of the Erazol pain reliever bottle. They were asked to rate their impressions of each picture with respect to the featured pain reliever on six 9-point 
semantic differential scales anchored at -4 and +4 (unattractiveattractive, inappropriate-appropriate, unrelated-related, dull-vivid, simplecomplex, boring-interesting). One "less-related" picture (featuring a house and a fence) and one "more-related" picture (featuring a hammock at the beach as depicted in Figure 1) were selected for the experiment based on the following criteria: significant differences in mean ratings of relatedness and appropriateness, no significant differences in mean ratings along the other three dimensions, no effects of age, and no interaction effects of age and any of the criteria. The less- versus more-related pictures selected received mean relatedness ratings of -2.03 and 1.90, $F(1,60)=12.91, p<.001$, respectively (with higher numbers indicating greater relatedness). For the appropriateness ratings, the less- and morerelated pictures obtained mean ratings of -2.33 and $1.92, F(1,60)=14.2$, $p<.001$, respectively (with higher numbers indicating greater appropriateness).

For the third pretest, yet another group of 35 younger and 35 older participants were asked to identify statements about pain relievers that were judged as relatively weak, versus strong, arguments. Participants were given a list of 30 statements representing brand claims and were required to rate each on two 9-point scales, first as to the persuasiveness of the statement ( 1 = "unpersuasive"; 9 = "persuasive") and second as to whether the statement represented a weak versus strong reason in favor of purchase ( 1 = "weak reason"; 9 = "strong reason"). Six statements with mean ratings of 4.60 for persuasiveness and 3.88 for strength of argument were selected for the weak-argument condition in the experiment. Six other statements with mean ratings of 6.00 for persuasiveness and 6.50 for strength of argument were chosen for inclusion in the strongargument condition. There were no age-related differences in these mean ratings $(F \mathrm{~s}<1)$.

\section{Procedure}

The main study was administered to groups of three to eight individuals either in the morning (between 8 and 10 A.M.) or in the late afternoon/early evening (between 4 and 6 P.M.). The individuals were randomly assigned to one of the treatment conditions and accordingly were not given a choice of session times. The older and younger adults participated in the study separately. Binder booklets representing the different argument strength by picture-relatedness conditions were randomly distributed to subjects. Participants were instructed to read the contents of the first page before they proceeded to view the ads contained in the binder. Included on this first page was an introduction, which served as a cover story to disguise the true purpose of the study. This introduction claimed that the sole purpose of the study was to seek the participants' thoughts and opinions about products featured in the ads they were about to view and that it was being done in cooperation with a marketing research firm. 
To ensure motivated processing of the ads, the introductory paragraph informed participants that they were part of a select group of universityaffiliated individuals whose opinions were being sought and that the study was co-administered by a local marketing research firm. Finally, participants were told that they would be allowed to choose a bottle of pain reliever from among six brands made available to them at the end of the experimental session. This procedure is consistent with what prior researchers have used to induce high involvement in their subjects (e.g., Petty, Cacioppo, \& Schumann, 1983; Miniard, Bhatla, Lord, Dickson, \& Unnava, 1991).

Approximately half the participants received the strong-argument version of the critical ad that contained statements affirming the effectiveness of the pain reliever (e.g., "designed for maximum relief," "quality is backed by years of research and development," "comes in tablets with a patented micro-thin coating that makes them easy to swallow"). The remaining half of the participants were given the weak-argument version of the ad that made no attempt to exhort the effectiveness of the pain reliever and instead referred to qualities of lesser significance (e.g., "designed to be easy to identify," "made to appeal to busy city dwellers," "tablets are offered in a variety of attractive colors and are designed to be pleasant-tasting"). The strong- and weak-argument versions of the Erazol ad were orthogonally crossed with pictures that varied in relatedness to the featured product.

After participants finished viewing the ads at their own pace, the binder was exchanged for a questionnaire booklet containing the critical dependent measures and manipulation checks. Upon completion of this first questionnaire, they were administered the Morningness-Eveningness Questionnaire (Horne \& Ostberg, 1976) for the purpose of determining each individuals' optimal time of day. The entire session took approximately 20 to 30 minutes, after which the subjects were debriefed and probed for suspicions about the study procedure or hypotheses. None of the subjects reported any suspicions that would warrant the exclusion of their data from further analyses. Subjects were then thanked for their participation and dismissed.

\section{Dependent Measures and Manipulation Checks}

The first task required participants to identify brand names featured in each of the ads they had just seen. This memory measure was collected to test the extent to which it accorded with attitude and cognitive response measures and thereby establish convergent validity for our findings. Participants were given a list of 20 brand names from which they were to identify the correct brand name for the nine product categories. However, only the response for the product of interest in this study was scored. If a participant selected the correct brand name for the pain reliever product category, the response was coded as 1 ; otherwise, it was coded 0 . 
Next, participants were asked to indicate their attitudes toward the Erazol product on 4 nine-point semantic differential scales. Scale values ranged from 1 to 9 with the following anchors: bad-good, unsatisfactorysatisfactory, unfavorable-favorable, not worthwhile-worthwhile. Because the inter-correlations among these measures were very high, responses were averaged to create an attitude index (Cronbach's alpha $=.97$ ) to assess a generally positive or negative attitude toward the product. These ratings were followed by a thought-listing task that instructed participants to list any thoughts or ideas that occurred to them as they viewed the Erazol ad.

The last section consisted of checks on motivation to process. Participants rated, on four separate nine-point rating scales, their levels of interest, motivation, involvement and attentiveness when they were looking through the ads in the binder.

\section{RESULTS}

\section{Manipulation Checks}

The main aim of the manipulation check was to test for age- and time of day-related effects on motivation to process information. A composite index of involvement was calculated by averaging the four ratings (Cronbach's alpha $=.89$ ) collected as manipulation checks for involvement. The mean rating of involvement was $M=6.60$; hence the experimental setting may be more appropriately viewed as inducing a moderate rather than a truly high level of motivation. More importantly, however, involvement did not significantly differ for the older $(M=6.72)$ and younger adults $(M=6.60), F<1$, and it did not significantly differ for those tested in the morning $(M=6.50)$ and the afternoon $(M=6.60)$. Thus any effects of argument strength and picture relatedness on attitudes could be attributed to differences in resources available at the time of processing and not motivation. There were no significant higher order interactions.

\section{Dependent Measures}

Analysis of variance was conducted on the main dependent measures of interest. Statistical tests $(F$-tests) are based on $(1,164)$ degrees of freedom with significance level for tests set at $p<.05$, unless otherwise noted.

Attitudes. The main hypothesis was that due to limited processing capacity, older adults would primarily rely on pictorial information for attitude formation in the afternoon (during their non-optimal time of day) and on argument strength in the morning (during their optimal time of day). Furthermore, it was hypothesized that due to greater processing capacity, younger adults would not be affected by the time of day manipulation. The attitude means relevant for testing these hypotheses are shown in Table 1. 
Table 1. Older Adults' Product Attitudes by Argument Strength, Picture-Relatedness, and Time of Day.

\begin{tabular}{cccccccc}
\hline & \multicolumn{2}{c}{ Morning (Optimal time of day) } & & \multicolumn{2}{c}{ Afternoon (Non-optimal time of day) } \\
\cline { 2 - 3 } & $\begin{array}{c}\text { Weak } \\
\text { arguments }\end{array}$ & $\begin{array}{c}\text { Strong } \\
\text { arguments }\end{array}$ & $\begin{array}{c}\text { Marginal } \\
\text { means }\end{array}$ & & $\begin{array}{c}\text { Weak } \\
\text { arguments }\end{array}$ & $\begin{array}{c}\text { Strong } \\
\text { arguments }\end{array}$ & $\begin{array}{c}\text { Marginal } \\
\text { means }\end{array}$ \\
\hline $\begin{array}{c}\text { Less-related } \\
\text { picture }\end{array}$ & 3.05 & 5.31 & 4.17 & & 3.94 & 3.71 & 3.85 \\
$\begin{array}{c}\text { More-related } \\
\text { picture }\end{array}$ & 3.26 & 5.75 & 4.46 & & 5.11 & 4.72 & 4.92 \\
$\begin{array}{c}\text { Marginal } \\
\text { means }\end{array}$ & 3.16 & 5.38 & & & 4.53 & 4.21 & \\
\hline
\end{tabular}

Younger Adults' Product Attitudes by Argument Strength, Picture-Relatedness, and Time of Day.

\begin{tabular}{cccccccc}
\hline & \multicolumn{2}{c}{ Morning (Optimal time of day) } & & Afternoon (Non-optimal time of day) \\
\cline { 2 - 3 } & $\begin{array}{c}\text { Weak } \\
\text { arguments }\end{array}$ & $\begin{array}{c}\text { Strong } \\
\text { arguments }\end{array}$ & $\begin{array}{c}\text { Marginal } \\
\text { means }\end{array}$ & & $\begin{array}{c}\text { Weak } \\
\text { arguments }\end{array}$ & $\begin{array}{c}\text { Strong } \\
\text { arguments }\end{array}$ & $\begin{array}{c}\text { Marginal } \\
\text { means }\end{array}$ \\
\hline $\begin{array}{c}\text { Less-related } \\
\text { picture }\end{array}$ & 4.64 & 6.50 & 5.60 & & 4.18 & 5.30 & 4.73 \\
$\begin{array}{c}\text { More-related } \\
\text { picture }\end{array}$ & 4.45 & 6.81 & 5.71 & & 4.79 & 5.74 & 5.27 \\
$\begin{array}{c}\text { Marginal } \\
\text { means }\end{array}$ & 4.55 & 6.72 & & & 4.51 & 5.50 & \\
\hline
\end{tabular}

Note: Attitude scores represent the average of four post-message attitude ratings on nine-point scales ( 1 = negative, 9 = positive).

As shown in Table 1, time of day exerted stronger effects on older adults than younger adults. Accordingly, a marginally significant four-way interaction of age, time of day, argument quality, and picture-relatedness was obtained, $F=2.85, p<.10$. The data for older adults are presented, followed by the data for younger adults.

For older adults, there was a significant three-way interaction of time of day, argument quality, and picture-relatedness, $F=3.96$. Decomposition of the interaction indicated that while argument strength determined attitudes in the morning (at their optimal time of day), $F=13.09$, picture-relatedness influenced attitudes in the afternoon (at their nonoptimal time of day), $F=6.11$. Specifically, attitudes toward the product were more positive in the morning, $F=32.14$, for strong $(M=5.53)$ versus weak argument $(M=3.16)$, but not in the afternoon, $F<1$ (see Figure 2, top). In the afternoon, attitudes towards the product were more positive when the picture was related to the product $(M=4.92)$ than when it was not $(M=3.85), F=5.17$; this was not the case in the morning, $F<1$ (see Figure 2, bottom).

For younger adults, a significant main effect of argument strength was obtained $\left(M_{\text {strong }}=6.07\right.$ vs. $\left.M_{\text {weak }}=4.51\right), F=14.29$ (see Figure 3 , top). No other significant effects related to time of day, picture-relatedness, or 

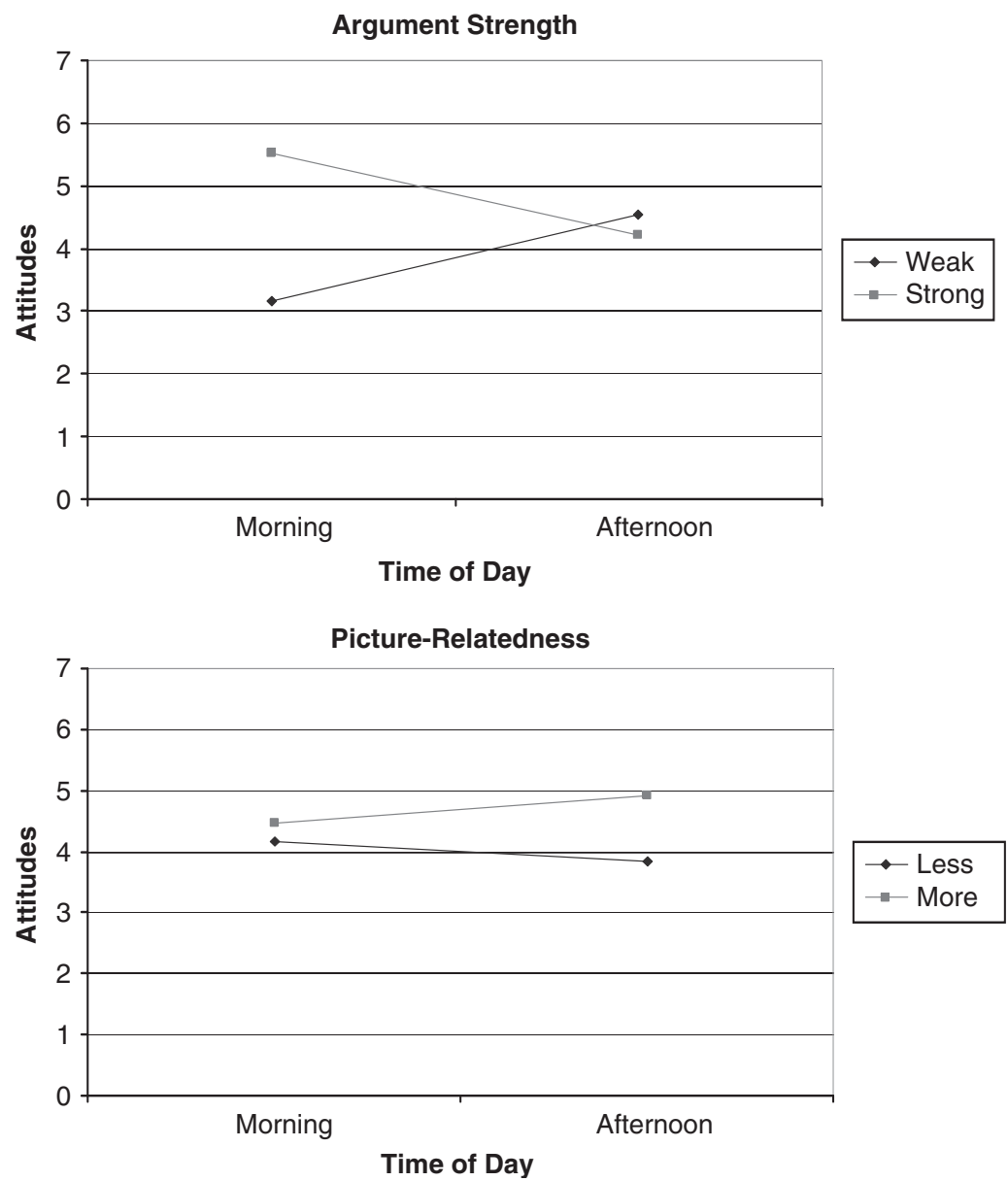

Note: Top panel shows the interactive effects of time of day and argument strength on older adults' attitudes. Bottom panel shows the interactive effects of time of day and picture-relatedness on older adults' attitudes.

Figure 2. Older adults' product attitudes.

any higher order interactions emerged $\left(F_{\mathrm{S}}<1\right)$. Thus, argument strength exerted an influence regardless of time of day. In contrast to older adults, the attitudes of younger adults were not influenced by picture-relatedness, $F=1.08, p=.30$ (see Figure 3, bottom).

The foregoing set of results suggests that resources available at optimal versus non-optimal time of day moderates older adults' reliance on argument quality and picture-relatedness for evaluation. These results are in marked contrast to those of younger adults, who relied on argument quality for evaluation both at their optimal and non-optimal times of day.

Cued Recognition. The hypotheses concerning the effects of time of day on message processing of older and younger adults predicts that time of day would more strongly affect cued recognition for older adults than younger adults. This prediction was confirmed by a significant interaction 

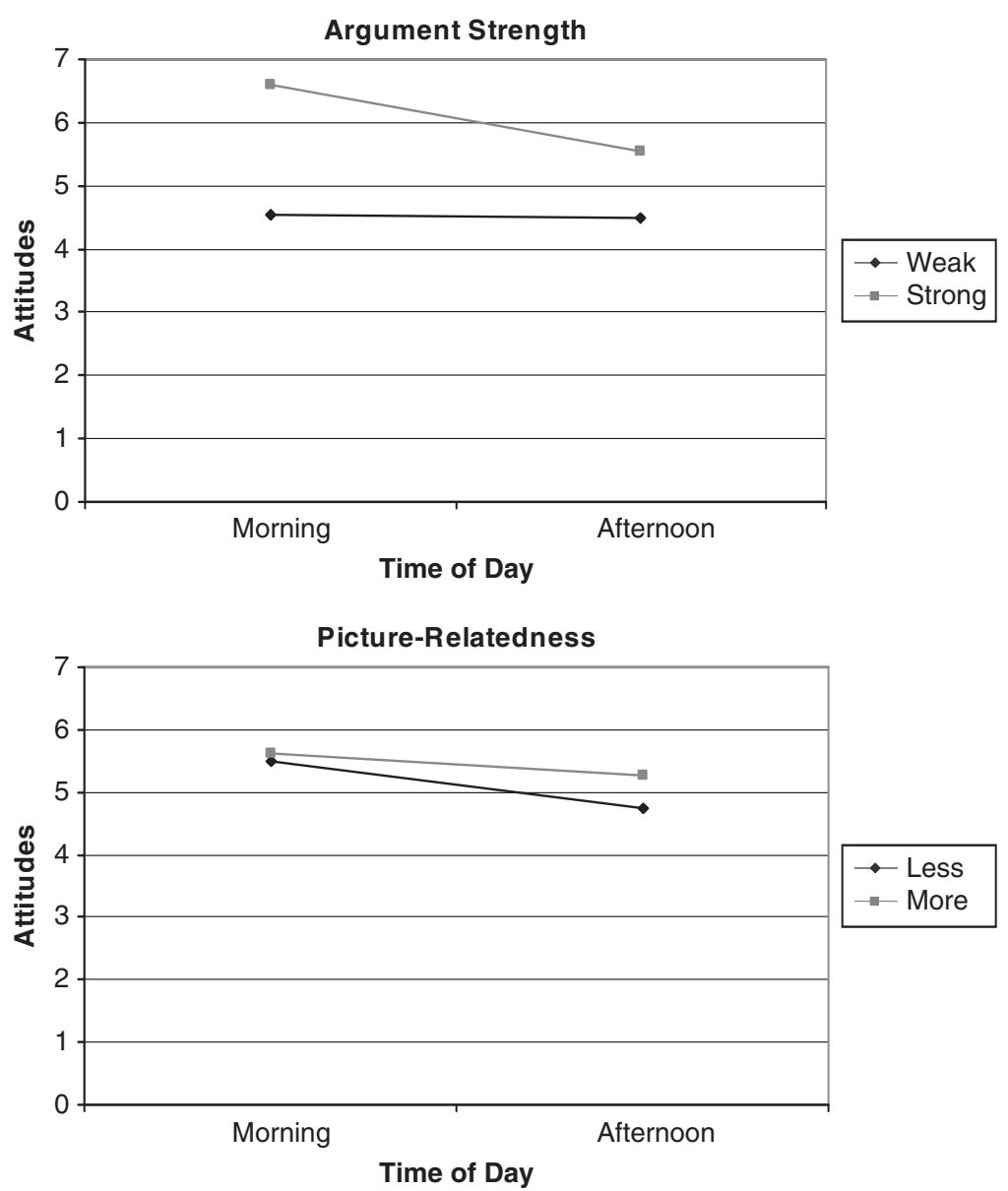

Note: Top panel shows the main effect of argument strength on younger adults' attitudes. Bottom panel shows the non-significant effect of picture-relatedness on younger adults' attitudes.

Figure 3. Younger adults' product attitudes.

of age and time of day, $F=5.42$. Specifically, whereas recognition performance by older adults was better in the morning $(M=.56)$ compared to the afternoon $(M=.32), F=6.89$, there was no difference in recognition performance for younger adults across time of day $\left(M_{\text {morning }}=.59\right.$ and $\left.M_{\text {afternoon }}=.62\right), F<1$. These results are consistent with the age-related findings concerning the effects of time of day on attitudes. Younger adults, even at their non-optimal time of day (morning), presumably had sufficient cognitive resources to engage in more effort-intensive processing. Older adults, in contrast, performed similarly to younger adults at their optimal time of day but more poorly at their non-optimal time of day (See Yoon, 1997, for a similar result pattern).

Cognitive Responses. To lend further support to the process-based explanation for the persuasion effects obtained, cognitive responses were 
analyzed. Participants' responses were first separated into individual thoughts by two independent judges who were blind to the study treatments and hypotheses. Each thought was classified as being related to the arguments in the ad, related to the picture in the ad, or neither (i.e., other). They were then coded as being positive, negative, or neutral. High inter-rater reliability $(>.92)$ was established for the coding and the few discrepancies were resolved by discussion between judges. Examples of positive and negative argument-related and picture-related thoughts are provided in the appendix.

Number of Thoughts. There was a significant interaction between age and time of day on the total number of thoughts generated $(F=4.19)$. Simple effects analysis revealed that while older adults generated more thoughts in the morning $(M=4.67)$ than in the afternoon $(M=4.07), F=$ 3.97, younger adults generated an equivalent number of thoughts across time of day $\left(M_{\text {morning }}=4.54\right.$ vs. $\left.M_{\text {afternoon }}=4.95\right), F=1.13, p=.29$.

Next, the proportion of thoughts relating to arguments and to picture relatedness were calculated by separately dividing the number of argument-related thoughts [PropARG], and the number of picture-related thoughts by the total number of thoughts [PropPIC]. According to the hypotheses, there should be a larger difference between PropARG and PropPIC for older adults than younger adults as a function of time of day. Specifically, for older adults the proportion of PropARG should be greater in the morning (at the optimal time of day) than in the afternoon (at the non-optimal time of day). In contrast, for younger adults the relative proportion of the two types of thought should not vary as a function of optimal time of day.

These predictions were supported. For older adults, there was a significant interaction of time of day and argument strength for Prop ARG, $F=6.94$. Tests of simple effects revealed that while the effect of argument strength on PropARG was significant in the morning during their optimal time of day $\left(M_{\text {weak }}=.39\right.$ vs. $\left.M_{\text {strong }}=.55\right), F=6.63$, this was not the case in the afternoon during their non-optimal time of day $\left(M_{\text {weak }}=.37\right.$ vs. $\left.M_{\text {strong }}=.30\right) ; F=1.44, p=.23$. In addition, there was a marginally significant interaction of time of day and picture-relatedness for PropPIC $(F=3.47, p=.07)$. Simple effects tests yielded a significant main effect of picture-relatedness on PropPIC in the afternoon $\left(M_{\text {less related }}=.30\right.$ vs. $\left.M_{\text {more related }}=.40\right), F=5.47$, but not in the morning $\left(M_{\text {less related }}=.30\right.$ vs. $\left.M_{\text {more related }}=.25\right), F<1$. Thus older adults generated more argumentrelated thoughts when they were persuaded by argument quality during their optimal time of day. By contrast, they reported more picture-related thoughts when they were persuaded by picture-relatedness during their non-optimal time of day.

For younger adults, PropARG was greater for strong $(M=.59)$ than weak arguments $(M=.38), F=21.15$, but it did not differ for those tested in the morning and those tested in the afternoon, $F=2.70, p>.10$. There were no other significant effects involving PropARG. Also, no significant 
effects obtained on PropPIC, $F_{\mathrm{s}}<1$. These findings provide process-level evidence that accords with results obtained for the attitudes. Younger adults generated more argument-related thoughts when persuaded by argument quality regardless of time of day.

Thought Valence. By subtracting the sum of the negative thoughts from positive thoughts, separate valence measures were obtained for argument-related and picture-related thoughts. ${ }^{4}$ Positive values on the index suggest more positive than negative affective responses, and negative values indicate more negative than positive affective responses.

There was a three-way interaction between age, argument strength, and time of day on the affective response index for argument-related thoughts $(F=7.38)$. Further analysis indicated that older adults had more positive thoughts in response to strong $(M=.92)$ than weak $(M=$ -.79 ) arguments in the morning, $F=19.88$, but not in the afternoon $\left(M_{\text {strong }}=-.33\right.$ vs. $\left.M_{\text {weak }}=-.37\right), F<1$.

For the younger adults there was a significant main effect of argument strength with more positive thoughts in response to strong arguments $(M=.83)$ and more negative thoughts in response to weak arguments $(M=$ $-.88), F=38.75$. There were no other effects involving argument strength.

With respect to picture-related thoughts by older adults, there was a marginally significant time of day by picture-relatedness interaction, $F=2.95, p<.10$. Specifically, older adults generated more positive thoughts in the afternoon when the picture was more related $(M=.50)$ than less related $(M=-.79), F=20.30$. The influence of picture-relatedness was much weaker in the morning $\left(M_{\text {more related }}=.35\right.$ vs. $M_{\text {less related }}=$ $-.37 ; F=4.29$ ). These results converge with the attitude data and provide further evidence consistent with our theorizing.

As has been the case throughout, time of day did not affect the processing of picture-relatedness for younger adults. For this age group, the number of positive relative to negative thoughts was greater when the picture was more related $(M=.24)$ compared to less related $(M=-.36)$, $F=9.79$, regardless of time of day.

\section{DISCUSSION}

The aim of this study was to investigate time-of-day effects on the processing of persuasion messages in older adults as compared to younger adults. Based on research demonstrating that the resources of older adults to process information at optimal (morning) and non-optimal (afternoon and evening) times of day varies markedly, the main hypothesis was that older adults would be differentially affected by easy- and difficultto-process information in a persuasion message as a function of time of

4 There were no significant effects of other (neutral) thoughts on any of the dependent measures. 
day. This prediction was consistent with both the heuristic-systematic model (Chaiken, 1980, 1987; Chaiken et al., 1989) and the ELM (reviewed in Petty, Priester, \& Briñol, 2002), which posit that even motivated participants will rely on easy-to-process information when sufficient cognitive resources are not available, while they will rely on argument strength when sufficient resources are available. The multiple measures employed, including attitudes, recognition, and cognitive responses, yielded convergent results, lending greater credence to the validity of the findings.

Generally, the results can be summarized as follows. First, the time of day when a persuasive message is received significantly affects the persuasion process for older adults. Older adults tend to be morning types who reach their cognitive peak early in the day. Time of day therefore places a constraint on their ability to engage in effort-intensive and systematic processing. Consistent with this line of reasoning, it was found that at their optimal time of day (morning), older adults' attitudes toward the product were more favorable when the arguments contained within the advertisement were strong and cogent. In contrast, at their non-optimal time of day, older adults' attitudes toward the product were more favorable when the picture was related to the pain reliever than when it was not. Second, younger adults were equally able to engage in detailed processing regardless of time of day (for a similar finding, see Yoon, 1997). Younger adults' ability to engage in processing of argument strength at both optimal and non-optimal times of day likely stemmed from the fact that they possessed sufficient resources to process the relatively simple persuasive message used in this study. Had a complex and thus more cognitively-demanding message been used instead, or had the participants been subjected to distraction or time pressure, time-of-day effects might well have been observed among the younger adults as well.

The authors acknowledge that the mean motivation ratings obtained from the study participants may suggest that the experimental procedure induced a moderately high rather than a high level of motivation. Importantly though, for each age group motivation levels were equivalent in the morning and afternoon, while reliance on argument strength and picture relatedness differed as a function of time of day only for the older participants. Thus, it does not seem probable that the time-of-day effects observed for the older participants resulted from differences in motivation. Moreover, for this age group at both times of day, the average motivation rating measures was significantly greater than the midpoint of the nine-point scale indicating relatively high motivation.

A potential methodological limitation of this study is that age and time of day were confounded-older subjects were all morning types, whereas younger subjects were all evening types. The atypical older adult who is an evening type was infrequent enough to be considered anomalous and thus was excluded from the analysis. Nonetheless, it would be 
interesting to see if these older adults would resemble the typical younger adult in their processing of persuasion messages. The authors suspect, however, that, given the reduced availability of cognitive resources for older adults in general, time of day will influence these evening-type older adults in the same manner that it affects morning-type older adults. That is, at their optimal time of day (evening), argument quality would play a significant role, whereas at their non-optimal time of day, a peripheral cue such as picture-relatedness would exert a greater judgmental influence.

The implications that follow from these findings have to do, first and foremost, with the need to explicitly take into account the rise and fall in the cognitive resources of older adults, over the course of a day, in the context of persuasive communications. Theoretical insights into persuasion processes have been based overwhelmingly on studies involving young adults. The literature on aging, on the other hand, is replete with evidence of changes in cognitive functioning across one's lifespan. This points to a gap in our understanding of persuasion processes in older adults, and the present study provides a step toward bridging that gap.

Decrements in cognitive function are characteristic of aging, and that is believed to limit the extent of thoughtful processing that older adults are able to carry out. Based on this assumption and the heuristicsystematic model (Chaiken, 1980, 1987; Chaiken et al., 1989) and the ELM (Petty, Priester, \& Briñol, 2002) frameworks, one might expect that older adults would be more likely to be persuaded by peripheral cues, such as the perceived relatedness of a picture in an ad or the perceived credibility of the source, than by the central merits of a message. The results of the present study suggest that this is not necessarily the case. One needs to take into account the time of day when processing of the persuasive message occurs. At their optimal time of day (when cognitive performance is at its peak), older adults are able to engage in more thoughtful processing, provided they are motivated to do so. The cogency of arguments, then, is key to affecting persuasion. There may, however, be a limited window of opportunity during which older adults are persuaded by merits of the arguments contained in a message.

A company that wishes to communicate a message to a target audience consisting of older consumers will be well advised to time the message in accordance with its complexity. Specifically, this study demonstrates that older adults are best reached in the morning when the message requires thoughtful or detailed processing, and they are conversely best reached in the evening when the message is simple or consists of favorable peripheral cues. Nevertheless, presenting the message at the optimal time of day, by itself, is not a sufficient condition to guarantee detailed processing. One needs to also ensure that the audience is motivated to process the message, perhaps by making salient at the outset the relevance of the product to the audience. The findings here have implications, 
in particular, for the advertising of medical or health-related products to older adults. The greater health concerns of this segment makes more likely the careful processing of messages dealing with health-related products, and it would therefore be prudent to ensure that advertising for such products present cogent arguments.

When the target audience consists of younger adults, on the other hand, the time of day at which the advertising message reaches the audience is not as critical a consideration, given that changes in cognitive ability over the course of a day are less significant for younger adults. The greater concern for a marketer may thus be the level of motivation with which the persuasive message is approached. This would determine the persuasive efficacy of argument quality relative to a peripheral cue such as source credibility. From a public policy perspective, the findings may also serve as a useful basis for developing programs to arm older adults with meta-knowledge about persuasion (Friestad \& Wright, 1994) to aid them not only in interpreting and responding to persuasive messages, but evaluating the effectiveness or appropriateness of persuasion attempts.

\section{CONCLUSIONS}

The significant changes that occur in cognitive ability as one ages systematically affect the processing of persuasive communications. This has implications not only for marketers interested in effectively reaching older consumers, but also for public policy makers interested in presenting information to older adults in a manner that serves their interest. It is the authors hope that a better understanding of the factors which influence the processing strategies and attitudes of older adults will lead to improvements in the design of communication programs aimed at older adults that contribute to effective decision making and successful aging.

\section{REFERENCES}

AARP Foundation (2003). Off the hook: Reducing participation in telemarketing fraud. Retrieved August 1, 2005, from http://assets.aarp.org/rgcenter/ consume/d17812_fraud.pdf

Burnkrant, R. E., \& Unnava, H.R. (1995). Effects of self-referencing on persuasion. Journal of Consumer Research, 22, 17-27.

Chaiken, S. (1980). Heuristic versus systematic information processing and the use of source versus message cues in persuasion. Journal of Personality and Social Psychology, 39, 752-766.

Chaiken, S. (1987). The heuristic model of persuasion. In M. P. Zanna \& J. M. Olson (Eds.), Social influence: The Ontario symposium, (Vol. 5, pp. 3-39). Hillsdale, NJ: Lawrence Erlbaum Associates.

Chaiken, S., Liberman, A., \& Eagly, A. H. (1989). Heuristic and systematic information processing within \& beyond the persuasion context. In J. S. Uleman \& J. A. Bargh (Eds.), Unintended thoughts (pp. 212-252). New York: Guilford. 
Craik, F. I. M. (1986). A functional account of the age differences in memory. In F. Clix \& H. Hagendorf (Eds.), Human memory and cognitive capabilities (pp. 409-422). Amsterdam: Elsevier.

Craik, F. I. M., \& Jennings, J. M. (1992). Human memory. In F. I. M. Craik \& T. A. Salthouse (Eds.), The handbook of aging and cognition (1st ed., pp. 51-110). Hillsdale, NJ: Lawrence Erlbaum.

Craik, F. I. M., \& Salthouse, T. A. (2000). The handbook of aging and cognition (2nd ed.). Mahwah, NJ: Lawrence Erlbaum Associates.

DeMarree, K., \& Petty, R. E. (in press). The elaboration likelihood model. In R. Baumeister \& K. Vohs (Eds.), Encyclopedia of social psychology. Thousand Oaks, CA: Sage Publications.

Friestad, M., \& Wright, P. (1994). The persuasion knowledge model: How people cope with persuasion attempts. Journal of Consumer Research, 21, $1-31$.

Hasher, L., Goldstein, D., \& May, C. P. (in press). It's about time: Circadian rhythms, memory, and aging. In C. Izawa \& N. Ohta (Eds.), Human learning and memory: Advances in theory and application. Mahwah, NJ: Erlbaum.

Horne, J. A., \& Ostberg, O. (1976). Time of day effects on extroversion and salivation. Biological Psychology, ), 301-307.

Kim, Y. K., Kang, J., \& Kim, M. (2005). The relationships among family and social interaction, loneliness, mall shopping motivation, and mall spending of older consumers. Psychology \& Marketing, 22, 995-1015.

Light, L. L. (1991). Memory and aging: Four hypotheses in search of data. Annual Review of Psychology, 42, 333-376.

Loroz, P. S. (2004). Golden-age gambling: Psychological benefits and selfconcept dynamics in aging consumers' consumption experiences. Psychology \& Marketing, 21, 323-349.

May, C. P., Hasher, L., \& Stoltzfus, E. R. (1993). Optimal time of day and the magnitude of age differences in memory. Psychological Science, 4, $326-330$.

Miniard, P. W., Bhatla, S., Lord, K. R., Dickson, P. R., \& Unnava, H. R. (1991). Picture-based persuasion processes and the moderating role of involvement. Journal of Consumer Research, 18, 92-107.

Nussbaum, J. F., Pecchioni, L. L., Robinson, J. D., \& Thompson, T. L. (2000). Communication and aging (2nd ed.). Mahwah, NJ: Lawrence Erlbaum.

Over 60 and overlooked: Marketing to the old. (2002). The Economist, August 10, 55.

Park, D. C., Puglisi, J. T., \& Smith, A. D. (1986). Memory for pictures: Does an age-related decline exist? Psychology and Aging, 1, 11-17.

Parry, C., \& Longman, B. (2004). Charge of the blue rinse brigade. Marketing Week, 27, 30-31.

Petty, R. E., \& Cacioppo, J. T. (1986). Communication and persuasion: Central and peripheral routes to persuasion. New York: Springer-Verlag.

Petty, R. E., Cacioppo, J. T., \& Schumann, D. (1983). Central and peripheral routes to advertising effectiveness: The moderating role of involvement. Journal of Consumer Research, 10, 135-146.

Petty, R. E., Priester, J. R., \& Briñol, P. (2002). Mass media attitude change: Implications of the Elaboration Likelihood Model of persuasion. In J. Bryant \& D. Zillmann (Eds.), Media effects: Advances in theory and research (2nd ed., pp. 155-198). Hillsdale, NJ: Erlbaum 
Reuter-Lorenz, P. A., \& Lustig, C. (2005). Brain aging: reorganizing discoveries about the aging mind. Current Opinion in Neurobiology, 15, 245-251.

Salthouse, T. A. (1991). Theoretical perspectives on cognitive aging. Hillsdale, NJ: Erlbaum.

Schewe, C. D., \& Balazs, A. L. (1992). Role transitions in older adults: A marketing opportunity. Psychology \& Marketing, 9, 85-89.

Spotts, H. E. Jr., \& Schewe, C. D. (1994). Communicating with the elderly consumer: The growing health care challenge. In P. D. Cooper (Ed.), Health care marketing: A foundation for managed quality (pp. 242-255). Gaithersburg, MD: Aspen.

Yoon, C. (1997). Age differences in consumers' processing strategies: An investigation of moderating influences. Journal of Consumer Research, 24, 329-342.

Zacks, R. T., Hasher, L., \& Li, K. Z. H. (2000). Human memory. In F. I. M. Craik \& T. A. Salthouse (Eds.), The handbook of aging and cognition, (2nd ed., pp. 293-357). Mahwah, NJ: Lawrence Erlbaum Associates.

Correspondence regarding this article should be sent to: Shai Danziger, Ben-Gurion University of the Negev, School of Management, P.O. Box 653, Beer-Sheva 84105, Israel (ShaiDanz@som.bgu.ac.il). 


\section{APPENDIX}

\section{EXAMPLES OF THOUGHTS}

\section{Argument-Related:}

\section{Positive}

- "The ad provided favorable information because it suggested that it would quickly take away your pain."

- "Erazol is not hard on the stomach, which is important."

\section{Negative}

- "There are no valid reasons for me to buy this product."

- "Concentrated on taste and looks—and nothing on test results."

\section{Picture-Related:}

\section{Positive}

- "The ad had a beautiful picture of a beach."

- "The ad had a picture of a sunny day, showing that the pill will promote happiness and relief."

\section{Negative}

- "The background picture of the advertisement is not strong enough to give the reader a clear view of the drug."

- "The picture there is not relevant." 